Viso - Cadernos de estética aplicada Revista eletrônica de estética

ISSN 1981-4062

№ 3, set-dez/2007

http://www.revistaviso.com.br/
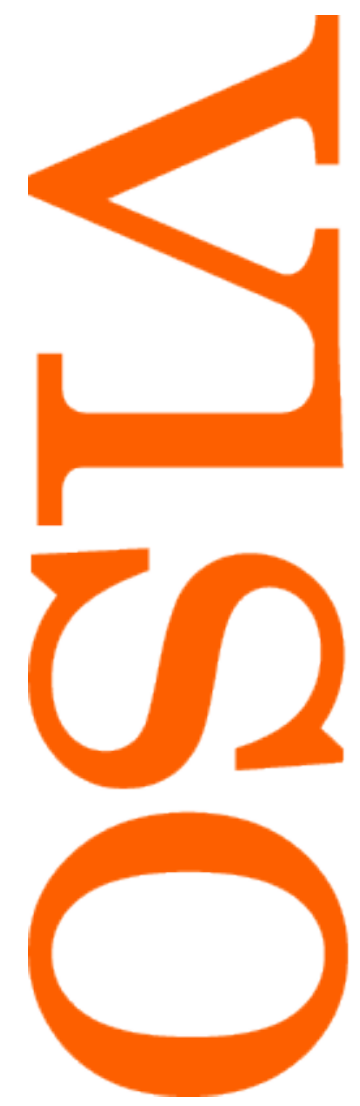

\title{
Entre Kafka e Heidegger: reflexões sobre a relação entre literatura e filosofia na era da técnica
} Marcia Cavalcante Schuback 


\section{RESUMO}

Entre Kafka e Heidegger:

reflexões sobre a relação entre literatura e filosofia na era da técnica

Este ensaio está dividido em três partes. A primeira consiste na leitura mais literal possível do conto de Kafka Der Bau, "A construção". A segunda parte é uma crítica à proposta feita por Deleuze e Guattari de uma leitura de Kafka sem filosofia, ou seja, evitando toda hermenêutica interpretativa. A terceira parte, mais extensa, discute a necessidade de uma leitura desse conto de Kafka não evitando a filosofia, mas acolhendo o entre filosofia e literatura, conectando esse conto de Kafka com a colocação de Heidegger sobre a questão da técnica.

Palavras-chave: estética alemã - literatura - Heidegger - Kafka

\section{ABSTRACT}

Between Kafka and Heidegger: Reflections about the relationship between literature and philosophy in the age of technique

This essay is divided into three parts. The first one presents Kafka's Der Bau [The Burrow] as literally as possible. The second one criticizes Deleuze and Guattari's attempt to read this work without philosophy, i.e., avoiding every hermeneutical interpretation. In the third and longest one, I argue that this short story demands a reading that does not flee from philosophy, but rather embraces the "in between" of philosophy and literature, connecting Kafka's text with Heidegger's observations about the question of technique.

Keywords: German aesthetics - literature - Heidegger - Kafka 
SCHUBACK, M. C. "Entre Kafka e Heidegger: reflexões sobre a relação entre literatura e filosofia na era da técnica". In: Viso: Cadernos de estética aplicada, v. I, n. 3 (set-dez/2007), pp. 56-69.

\subsection{9/1981-4062/v3i/47}

Aprovado: 02.12.2007. Publicado: 27.12.2007.

(C) 2007 Marcia Cavalcante Schuback. Esse documento é distribuído nos termos da licença Creative Commons Atribuição-NãoComercial 4.0 Internacional (CC-BY-NC), que permite, exceto para fins comerciais, copiar e redistribuir o material em qualquer formato ou meio, bem como remixá-lo, transformá-lo ou criar a partir dele, desde que seja dado o devido crédito e indicada a licença sob a qual ele foi originalmente publicado. Licença: http://creativecommons.org/licenses/by-nc/4.0/deed.pt_BR

Accepted: 02.12.2007. Publicado: 27.12.2007.

(C) 2007 Marcia Cavalcante Schuback. This document is distributed under the terms of a Creative Commons Attribution-NonCommercial 4.0 International license (CC-BY-NC) which allows, except for commercial purposes, to copy and redistribute the material in any medium or format and to remix, transform, and build upon the material, provided the original work is properly cited and states its license.

License: http://creativecommons.org/licenses/by-nc/4.0/ 
Este ensaio está dividido em três partes. A primeira consiste na leitura mais literal possível do conto de Kafka Der Bau, "A construção". A segunda parte é uma crítica à proposta feita por Deleuze e Guattari de uma leitura de Kafka sem filosofia, ou seja, evitando toda hermenêutica interpretativa. A terceira parte, mais extensa, discute a necessidade de uma leitura desse conto de Kafka não evitando a filosofia, mas acolhendo o entre filosofia e literatura, conectando esse conto de Kafka com a colocação de Heidegger sobre a questão da técnica.

\section{Lendo o conto de Kafka em sentido literal}

Der Bau - "A construção" - é um dos últimos contos de Kafka. ${ }^{1}$ O conto começa narrando sobre uma construção acabada. A primeira linha do conto está em tempo passado - "instalei a construção e ela parece bem-sucedida", Ich habe den Bau eingerichtet...${ }^{2}$ Esse tempo passado logo haverá de mostrar-se como o tempo mais estranho no conto, uma vez que o tempo predominante na narrativa é o tempo presente. ${ }^{3}$ $E$ isso porque a construção acabada é, na verdade, uma construção que não cessa e não se cansa de construir, mudando e renovando a construção a fim de assegurar e preservar a construção. A construção é um estar em construção, é um em se construindo. ${ }^{4}$ Esse em-construção, em-se-construindo indica, ainda, o paradoxo de já se estar dentro da construção para ser possível adentrar a construção. Como podemos ler no começo do conto:

Por fora é visível apenas um buraco, mas na realidade ele não leva a parte alguma, depois de poucos passos já se bate em firme rocha natural. [...] A uns mil passos de distância dessa cavidade localiza-se, coberta por uma camada removível de musgo, a verdadeira entrada da construção, $[\ldots . .]^{5}$

A verdadeira entrada não é o buraco. O buraco apenas cobre e encobre a entrada. É que a entrada precisa ser camuflada para que se possa proteger a construção, "ela está tão segura quanto algo no mundo pode ser seguro" contra invasões e ataques externos, "existem muitos que são mais fortes do que eu e meus adversários são incontáveis, poderia acontecer que, fugindo de um inimigo, eu caísse nas garras de outro". ${ }^{6}$ De fato, a construção aparece como a mais vulnerável e, portanto, como a que precisa ser continuamente protegida - gerúndios. O construtor, o autor, "não tenho uma hora de completa tranqüilidade", sendo vulnerável nesse "ponto escuro do musgo", vendo em sonhos "um focinho lúbrico". O construtor diz, no entanto, que não é por medo que a construção está sendo feita. É por falta de tranqüilidade, por um sentimento de se estar sendo continuamente ameaçado, que surge a necessidade de assegurá-la. A construção faz-se por uma necessidade incontrolável de controlar cada parte e espaço da construção e de evitar que todo elemento estranho, que toda alteridade, adentre a construção.

O construtor vive dentro da construção, ameaçado tanto por inimigos externos como por inimigos internos provindo dos confins da terra. A construção só possui uma entrada e 
saída: o desespero do construtor é que a entrada de outros, sejam os outros de fora ou os outros de dentro, deve ser evitada ao mesmo tempo em que, no caso de ataque, a possibilidade de uma saída para o construtor seja assegurada. Contudo, entrada e saída são a mesma - todo porta é o paradoxo de ser, ao mesmo tempo e de uma só vez, entrada e saída. O paradoxo da porta expressa a iminência terrível de um perigo por vir, que não deixa o construtor ter nenhum momento de tranqüilidade.

Além da entrada, há um outro elemento gerador de muita angústia. Trata-se do centro da construção, que coloca a questão de como assegurar provisões para se sobreviver dentro da construção. Ambas as questões: a questão da porta - evitar a entrada de qualquer outro, assegurando ao mesmo tempo a saída - e a questão do centro sobreviver dentro, ou seja, sobreviver sem o fora - obrigam o construtor à construção contínua, gerundial e incansável. Temos aqui um resumo muito sumário da primeira parte desse conto de Kafka onde a construção está sendo descrita de dentro.

$\mathrm{Na}$ segunda parte do conto, o construtor sai da construção, vai para fora, adentra o aberto de fora. Todavia, o aberto é para ele tão somente a possibilidade de olhar para o buraco de fora, de modo a investigar soluções mais seguras para os seus dilemas. $\mathrm{Na}$ segunda parte, a construção é descrita de fora. Esse fora da construção é narrado como um Oberwelt, um mundo acima e aberto relativamente à construção, chamada agora de Unterwelt, um mundo debaixo, subterrâneo, fechado dentro da terra. O fora, o acima, o aberto, esses termos compõem a geografia do outro do que a construção, mas que é tão somente o lugar para se observar a construção com vistas a assegurar a sua absoluta interioridade e imanência. A construção aparece como o paradoxo de um dentro que está fora e um fora que está dentro.

Na terceira parte do conto, o construtor volta para dentro da construção. "A construção" é a Odisséia de Kafka. Nessa parte, o pronome "tu", um "tu" muito estranho, expresso tanto no singular como no plural "vós", Du e Euch, pronuncia-se pela primeira vez. O construtor chama agora de "tu" a própria construção, as suas passagens e espaços. Parece que o fora do dentro concedeu ainda mais poder à interioridade da construção. $A$ construção é o "tu", o trabalho, que pode ser observado pelo construtor enquanto a construção se faz. Nesse momento de reflexão, o construtor pode finalmente dormir. Mas justamente então, um "zumbido", quase inaudível, desperta o construtor. O zumbido intensifica-se, tornando-se insuportável. O construtor começa a raciocinar até quase à loucura sobre a razão desse zumbido, sobre a sua proveniência. O construtor lembra-se de um episódio do começo da construção e alude a um pararelo entre ele e o zumbido. Mediante esse paralelo, uma terceira pessoa, um "ele" pronucia-se pela primeira vez. Talvez esse terrível, insuportável, crescente zumbido venha de um estranho animal, provenha de um "grande animal", diz o construtor, e não de um animal pequeno. Mas se é mesmo assim, então esse grande animal ruidoso já deveria ter sido ouvido pelo construtor em sua construção. Talvez esse "ele" nada mais seja do que o construtor ele mesmo. E se tudo e todos, nada e ninguém no conto estão fora desse si-mesmo, tudo 
mantém-se desprovido de alteridade, tudo mantém-se inalterado. "Mas tudo continuou inalterado", aber alles blieb unverändert. O passado reforça o presente. Assim acaba o conto.

\section{Um modo de ler o conto evitando a filosofia, evitando a interpretação (uma crítica à leitura de Deleuze e Guattari ou o perigo do intelectualismo)}

Sem dúvida, é bastante 'literariamente incorreto' resumir um conto como esse de Kafka. Essa incorreção é, no entanto, o que de fato acontece quando lemos qualquer conto. Lemos, guardamos certas passagens na mente, recontamos, corrompemos, interrompemos, etc. Os contos de Kafka são de tal modo que eles mesmos fazem isso conosco. Não é possível simplesmente lê-los e perguntar sobre o seu sentido. A leitura já é, no seu próprio acontecer, um questionamento sobre o que é uma leitura. Os contos de Kafka não estão apenas contando sobre hiper- ou hiporrealidades kafkianas. No que contam, eles contam sempre e ao mesmo tempo sobre o kafkiano do que é ler e interpretar. Esse é um ponto de partida para as leituras de Kafka propostas por Deleuze e Guattari. Nessas leituras, eles proclamam Kafka um escritor político e não um escritor para ser interpretado.

O ponto de partida dessa leitura é a oposicão entre política e hermenêutica, hemenêutica entendida tanto filosoficamente como no seu uso na teoria literária. O político é definido nessa leitura por oposição à interpretação, em quatro aspectos: a) o escritor político é visionário de um mundo futuro (o mundo da burocracia global, nosso admirável mundo novo); b) o escritor político exibe uma micro-política entendida como política do desejo questionadora de todas as instâncias; c) o escritor político faz experimentos e não literatura; d) o escritor político é um escritor experimental que deve ser visto como um nômade em fuga para o socialismo, o anarquismo e movimentos sociais. Nesse sentido de político, a obra de Kafka não deve ser interpretada no sentido de se buscar reconduzir suas diversas expressões literárias como cartas, contos, romances para uma forma arquetípica, ou seja, para uma forma conceitual ou imaginária. Tampouco o seu trabalho deve ser lido através de livres associações que acabariam aterrando nas memórias da infância do intérprete. A obra de Kafka também não deve ser lida como se alguma coisa significasse outra. No quadro metodológico proposto por Deleuze e Guattari, e que ermege dessas negociações mencionadas, uma leitura política de Kafka, assumido como um escritor político, deve investigar a escritura de Kafka como uma máquina e como experimentos onde o homem se transforma em animal, onde a literatura de sentidos transforma-se em uma máquina de vozes, sons e estilo (traços de animalidade).

Não vou discutir certas contradições implicadas nessas afirmacões. Basta apontar para o fato de que, na proposta de leitura sem interpretação, Deleuze e Guattari assumem o conto Metamorfose como arqui-arquétipo de todos os contos de Kafka e O Processo como arqui-arquétipo dos romances. Essas duas obras são assumidas como entrada e chave para a obra de Kafka. Podemos objetar que esses arquétipos contradizem a 
resposta que eles dão à questão "como adentrar a obra de Kafka?" ao afirmarem que, para essa obra, há múltiplas entradas e portas. Não vou discutir aqui essa resposta sedutora e as suas contradições. Sedução e contradição são sem dúvida a melhor parte tanto da filosofia como da literatura. O que falta, porém, nessa contradição não é a coerência mas justamente $\mathrm{o}$ acolhimento da contradição, o deixá-la viver contraditoriamente e, nela, o acolhimento dos arquétipos, pois linguagem é sempre obra de arqui-arquétipos. Mas essa não é minha questão aqui. $O$ que cabe questionar não são tanto as respostas, mas a questão que abre as discussões de Deleuze e Guattari. Pode alguém adentrar a obra de Kafka? Lendo $A$ construção e já na primeira linha "instalei a construção", deveríamos dizer ao contrário: não é possível entrar no mundo de Kafka porque já sempre nele estamos, porque já sempre estamos "aí". Esse fato constitui o kafkiano da obra de Kafka: o fato de já sempre estarmos dentro dela, sem que nos seja possível nela entrar ou dela sair. Na Construção nós já sempre estamos e somos como já sempre somos no ser, ou seja, não sendo capazes de nele adentrar e nem dele sair. Wir sind schon da. Gostaria de propor que esse "já somos e estamos sempre aí", wir sind immer schon da - essa facticidade da existência deve ser entendida como o fato do político. Nesse sentido, pode-se entender igualmente o que Heidegger quer dizer ao afirmar que o "Da" de Dasein, o "pre" da presença deve ser entendido como pólis, em sentido grego.

\section{Lendo o conto de Kafka "A construção" sem evitar filosofia (ou intrepretação) e acolhendo o entre literatura e filosofia.}

Já sempre estamos dentro da construção. Digo "nós" e tenho em mente nós, os construtores. Mas quem somos "nós", ou seja, os construtores? Nós somos os animais no sentido de seres animados, de seres possuidores de alma, anima. No conto de Kafka, o construtor é, no entanto, um tipo particular de animal, um tipo particular de alma viva, pois é uma alma narradora raciocinante, é uma alma racional. O construtor nesse conto não apenas verfertigt, realiza sem pausa e descanso, mas, enquanto cumpre, realiza, constrói e trabalha, ele fala e narra no modo de uma razão auto-justificadora, no modo de uma Rechtfertigung. ${ }^{7}$ Narrar/falar e raciocinar - literatura e filosofia - estão conectados. Essa conexão entre narrar e racionalizar, entre literatura e filosofia, é o fundo estranho de onde a definição do homem como animal racional, como ser vivo dotado de linguagem, foi enunciada pelos antigos gregos. Desde os gregos, essa conexão entre narrar e raciocinar, entre literatura e filosofia, foi descrita como uma relação de conflito. Ela exprime o conflito do humano abandonando a animalidade, entendida como natureza cósmica da alma, como alma do mundo, anima mundi, alma do aberto. O processo em jogo na construção narrativa-raciocinante não é o processo do homem tornando-se animal, mas do homem abandonando a animalidade entendida como o aberto (a anima mundi). Gustav Janouch conta que Kafka disse-lhe o seguinte a respeito da relação entre o homem e o animal: 
O parentesco com o animal é bem mais fácil do que com os homens [...]. Cada um de nós vive atrás de uma grade, que carrega consigo por toda parte. É por isso que hoje se escreve tanto sobre o animal. Isso exprime a nostalgia de uma vida livre e natural. Para o homem, porém, a vida natural é a vida humana. Isso ninguém quer ver. A presença humana é demasiado incômoda, e por isso quer-se dela desvencilhar-se, nem que seja só na fantasia. ${ }^{8}$

Como em qualquer outro conto literário e qualquer outro conto de Kafka, "A construção" pode ser lida de vários modos, sob diferentes perspectivas e visões. Mas o que mais chama atenção nesse conto é o fato de o "si mesmo" dentro da construção mostrar, ao mesmo tempo, a construção do interior de um "si mesmo". Esse conto trata da construção, da caverna do si mesmo, dessa poderosa imagem ocidental de um "em si mesmo" [auto, kath'auto, en auto]. A caverna de Platão, as notas do subsolo de Dostoievski estão com-preendidas na "Construção" de Kafka. Dentro-fora, submundo, supramundo, imanência-transcendência, física-metafísica, essas semânticas da oposição entre verdade e falsidade, abstração e ficção, filosofia encontrando ou evitando a literatura e vice-versa são, sem dúvida, remissões possíveis e justas, mas lendo "A Construção" em seus próprios termos, e não como experimento, não como política, não como máquina, lemos as ambigüidades infinitas desse "já sempre estar dentro/na Construção", desse "ser-na-construção", Im-Bau-sein: pois não é por medo que o animal narrador-racional está lá, mas porque ele não pode não ser e estar lá, aí, ele não pode não ser na presença. Ele é esse "pre": aqui, lá, não são opções; a construção é o mundo desse animal; ele é seu mundo.

Contudo, o terrível, o perigo é que a "Construção" torna-se tão identificada com o construtor, que ela se torna inteiramente desmundanizada, desprovida de mundo. Não há mundo nesse mundo. Sendo na construção, sendo em seu próprio mundo inteiramente absorvida nesse estar sendo, significa, paradoxalmente, tornar-se desprovido de mundo. Essa é uma ambigüidade central da construção. A construção é o ser desse animal, seu modo de ser, seu sentido, seu fundamento. Esse animal não tem fundamento, não tem sentido, não tem ser fora da construção. O fora dela, o supramundo, o ar livre não tem nele mesmo nenhum sentido a não ser enquanto assumido como o fora desse dentro da construção, dentro do mundo do animal. Essa absoluta imanência da construção atesta o sem sentido de todo fora, de toda alteridade.

Outra ambiguidade central da construção reside no fato de a sua interioridade, de a construção estar sempre ajustando, ajeitando, operando, trabalhando, construindo, numa contínua e incansável alteração para assim tudo manter inalterado. Alterar tudo todo o tempo é o modo de assegurar e evitar a entrada de toda e qualquer alteridade. Com efeito, em seus próprios termos, a construção é o fazer aparecer a ambigüidade de serna-construção, onde todo sentido mistura-se e confunde-se com seus sentidos opostos e contraditórios. A construção não é ambígua; ela é uma construção dentro da ambigüidade. A ambigüidade mais central é aquela relacionada à porta para dentro e fora da construção, à porta que é a mesma para entrar e sair. 
O animal narrador-escritor-raciocinante-racionalizador constrói sem descanso a fim de assegurar a possibilidade de saída e, ao mesmo tempo, evitar a entrada de outros animais, a entrada do outro. Em sua incansável construção, em sua narrativa literária, o construtor aparece como um prisioneiro de sua própria construção. Se construções testemunham a presença de uma alma e assim de um certo tipo de transformação que tanto obedece como desobedece a natureza, e se esse testemunho construtivo atesta, por sua vez, liberdade, no entendimento moderno de liberdade como liberdade da natureza, como técnica, então esse animal narra a sua prisão na liberdade. $O$ construtor técnico é um prisioneiro de sua liberdade. E ainda, se liberdade significa soberania para o controle, esse animal narra sobre o ser controlado pelo seu próprio desejo de controle e de exercer poder. Ele narra o ser um impotente escravo de seu próprio poder. Sem mundo em seu próprio mundo, controlado pelo seu próprio controle, impotente em seu próprio poder, não possuindo nenhum meio no mundo que não seja um intermediário de si mesmo (no conto, o animal nem sequer usa ferramentas, pois usa sua própria testa como ferramenta universal), alterando tudo para tudo permanecer inalterado, não confiando em ninguém, nem em algum amado e nem em algum deus por se fiar apenas em si mesmo, esse animal narrador-escritor-raciocinante-racionalizador é um não ser em seu próprio ser.

Na conferência intitulada "Identidade e diferença", Heidegger discute a constelação que "hoje" rege a relação entre homem e ser. "Constelação de ser e homem" é uma expressão tardia de Heidegger para discutir a questão da facticidade, esse "já ser sempre dentro", "wir sind schon da". Heidegger descreve essa constelação como Bau, como uma construção, entendida como essência da técnica moderna, como Ge-stell. Nessa leitura, Heidegger quer mostrar que Ge-stell (enquadramento, armação), a essência da técnica moderna é um prelúdio para o Er-eignis, para o acontecer apropriador de ser como tal. Enquanto o perigo mais perigoso, por ser possibilidade de total destruição, de total esquecimento, enquanto processo de um homo desumanisans e de uma natura denaturata numa extensão incontrolável e planetária, a técnica contemporânea é em sua essência - Ge-stell - ainda a techné grega, ou seja, um destino de desencobrimento, de alétheia, de verdade. Ge-stell é destino de verdade mas no modo trágico de fazer aparecer verdade como desencobrimento encobrindo o sentido de verdade como desencobrimento. Nesse modo, verdade como desencobrimento descobre-se encobrindo-se em contínuas ambïgüidades. Ge-stell é, portanto, uma construção, uma Bau das ambigüidades, onde bom é mal, mal é bom, onde uma palavra salvífica é mortal, onde liberação significa tanto racionalidade técnica como irracionalidade religiosa, onde parece impossível distinguir entre perigo e salvação. Com efeito, as discussões de Heidegger sobre a essência da técnica e de seus paradoxos uma humanidade tornando-se inteiramente escrava de sua liberdade, impotente em seu poder, etc - são tão próximas da descrição kafkiana da construção que parece fácil e mesmo evidente usar o conto de Kafka como "ilustração" ou "exemplo", como "metáfora" da descrição heideggeriana da técnica planetária. Nesse modo, Walter Biemel leu Kafka e esse conto em particular em conexão com a questão da técnica desenvolvida por 
O uso da palavra Bau em "Identidade e diferença" difere e ilumina, porém, de outro modo, as reflexões de Heidegger sobre o construir e habitar humanos na célebre conferência "Bauen, Wohnen, Denken", "Construir, habitar, pensar". ${ }^{10}$ Esse uso diferente o torna ainda mais próximo de Kafka. A questão que investiga se Heidegger leu ou não Kafka - Walter Biemel afirma que Heidegger não leu Kafka ${ }^{11}$, Agambem afirma que Heidegger lhe disse ter lido de Kafka unicamente "A construção"12 - fica de certo modo resolvida quando lemos a correspondência com H. Arendt, pois ali vê-se que Heidegger leu um pouco de Kafka. ${ }^{13}$ Isso importa pouco. Em questão para nós é como a construção kafkiana poderia ser compreendida por Heidgeger. Nessa mesma conferência ("Identidade e diferença"), podemos ler o que eu considero uma chave para essa questão: Heidegger pergunta-se sobre como a essência da técnica, Ge-stell, é um prelúdio para o Er-eignis, ou seja, como uma relação técnica e assim não pensante com o ser pode tornar-se um pensar relacional com o ser enquanto evento-apropriação. Para Heidegger, esse prelúdio consiste no desafio de uma construção nessa oscilação, de uma construção ambígua - Das Er-eignis als Er-eignis denken, heisst, am Bau dieses in sich schwingenden Bereiches bauen. ${ }^{14}$ "O pensamento", continua Heidegger, "recebe da linguagem as ferramentas para essa construção auto-suspensa. Pois a linguagem é a oscilação mais delicada e assim mais suscetível que tudo sustenta dentro da construção suspensa do evento-apropriação". ${ }^{15}$ Nesse sentido, o conto de Kafka, "A construção", não é somente uma "ilustração", uma "imagem" ou "exemplo" literários da técnica planetária, mas ele mesmo a construção dentro dessa construção oscilante e ambígua. Ele conta que, enquanto construção contínua com vistas a controlar todos os eventos possíveis, a técnica já é nela mesma um evento-apropriação. Em outras palavras: fazendo a experiência dura e trágica de que o homem técnico de hoje é o homem inteiramente controlado pela sua própria vontade de controlar, mostra-se que o construtor não é capaz de controlar a sua própria vontade de controle. Ou seja: tudo controlando, o construtor não é capaz de tudo controlar. Isso significa que, no seu máximo controle, o construtor faz a experiência de sua falta de poder e, assim, dos limites da lógica do controle. O "sem saída", o "não ter para onde escapar", uma vez que o próprio fora nada mais é do que o fora do dentro, justamente o não ter para onde ir mostra-se como o lugar em que tem lugar uma abertura. A abertura não está nem acima e nem fora. Está dentro. "Onde mora o perigo ali também cresce a salvação" (Hölderlin). Porque a abertura está dentro da construção, tem lugar um outro sentido de diferença. Não se trata mais da diferença entre dentro e fora, mas de diferenciação dentro da diferença. Trata-se de diferença enquanto evento-apropriação. Na "Construção", onde a diferença relativamente à identidade torna-se inteiramente sem sentido, nada mais sendo do que ambigüidade, é possível o surgimento de um outro sentido de diferença que é a diferenca entre identidade e diferença. A constelação entre ser e homem, usando os termos de Heidegger, é uma relação ambígua, é hoje o não-relacionamento entre ser e homem na construção ambígua da técnica planetária. Todavia, em jogo está a possibilidade de se conquistar uma outra constelação dentro dessa construção ambígua 
- wir sind schon da; já somos no ser, já somos na construção. Um pensamento do ser enquanto evento- apropriação pode apenas surgir de dentro do esquecimento total de ser se esse pensamento acontecer como uma diferenciação e não como simples diferença. Como sua diferenciação, ele consiste no habitar na claridade do entre, deixando para trás a idéia de diferença enquanto lógica e dialética dos opostos, oposições, contrastes, contradições.

Mas as "ferramentas", como diz Heidegger, para esse outro pensar devem ser propiciadas pela linguagem. Deve ser uma construção na construção ambígua da realidade que é igualmente uma construção da linguagem. É nesse sentido que o encontro entre filosofia e literatura não somente é inevitável e salutar, mas o mais urgente. A questão não é, portanto, nem evitar a filosofia (entendida como hermenêutica e interpretação) nem acolher a literatura na filosofia como uma questão de estilo, de objeto ou temática de investigação. A questão é mais grave. É de como habitar e, assim, construir e, assim, de como pensar entre filosofia e literatura. No meu entender, essa questão pode encontrar acenos inspiradores em certos aspectos se seguirmos esse encontro entre filosofia e literatura no encontro entre Heidegger e Kafka. Nesse encontro, algumas distinções de princípio devem ser colocadas.

Filosofia e literatura não se encontram ou se separam porque literatura é ficção e filosofia abstração. ${ }^{16}$ Nesse entendimento comum, literatura e filosofia poderiam encontrar-se porque ambas são distanciamentos da realidade: a primeira por meio da ilusão e a segunda por meio da abstração. Do ponto de vista da experiência de um acontecer, a literatura nada mais é do que o acontecimento da linguagem e a filosofia o acontecimento do pensar. Isso significa que, tanto na literatura como na filosofia, é a realidade que descobre um sentido bem mais real do que aquele de objetividade, à base da distinção entre ficção e abstração. A objetividade não é suficientemente real, nem para a literatura nem para a filosofia, à medida que ambas se definem desde o seu próprio acontecer.

O encontro entre filosofia e literatura não é nada novo, ou algo que só teria lugar entre Kafka e a filosofia contemporânea. A filosofia definiu-se desde os antigos gregos num encontro ou, melhor, num desencontro com a poesia. Sem dúvida, podemos dizer que tanto a poesia como a literatura são arte; pode-se igualmente considerar que a essência da arte é a poética, entendendo por poética o deixar aparecer o aparecer como tal e, assim, a experiência de devolver à arte o seu valor de enigma, para relembrar uma bonita passagem de Paul Valéry. Mas em seu sentido restrito, poesia não é literatura. Se tanto a poesia como a literatura devolvem ao ser e à linguagem o seu valor de enigma, elas o fazem em modos bem singulares e distintos. A poesia está resguardada no elemento de uma intimidade, que pode ser tanto pacífica como conflitual, com a língua falada, ou mais precisamente como o espaço de jogo entre som e silêncio. Mas e a literatura? Literatura é escrita, é palavra escrita, é texto. Nesse sentido, a filosofia parece ainda mais próxima da literatura do que da poesia. Os gregos, pensando aqui sobretudo 
em Platão, consideraram o texto inferior à palavra falada, porque na escrita a palavra torna-se imóvel, fixa, perdendo o ar- elemento da linguagem, a dança dos gestos, do corpo, das entonações, das presenças e ausências de quem fala e de quem escuta. A escritura está, por sua vez, resguardada no elemento da rigidez, da permanência, do isolamento, do fechamento, tendo por elemento não o ar mas a pedra, prometendo a eternidade e a solidez de um sentido. Por isso, costumamos acreditar mais nas palavras escritas, porque parecem prometer um real mais real do que a realidade, um real permanente. A escrita parece prometer literalidade, objetividade, uma realidade ainda mais real. Todavia, nada nega mais profundamente essa caracterização da palavra escrita do que a literatura. Literatura está mais oposta à literalidade do que a palavra falada. Sua oposição é ainda mais radical porque emerge de dentro da literalidade da palavra escrita. Literatura é essencialmente luta. É luta bem antes de tornar-se engajada. Literatura é rebelião ao seu elemento de dentro do elemento. É a emergência de um novo sentido de dentro de um sentido fechado e rígido, de dentro de um sentido sem saída, sem foras. Esse rígido elemento de literalidade - sentidos literais - nutre-se ele mesmo da capacidade de dizer no presente o que já foi dito. Ao lermos uma linha, quer escrita há mil anos atrás ou há um minuto atrás - lemos no presente, e o já dito faz-se presente e por vezes até faz-se presença. Isso explica porque o elemento rígido de literalidade está muito próximo de um outro elemento rígido e fechado, que é o elemento de uma "vida nas letras", no sentido em que falamos de um "homem de letras", do "letrado", da linguagem escrita, quando língua escrita significa erudição, intelectualismo os monumentos e a monumentalidade do já ter sido dito, da repetição, da citação. As bibliotecas de Borges! O homem que não consegue esquecer de Nietzsche!

Contudo, literatura não é nem a medianidade da literalidade e nem a futilidade de "uma vida das letras". Pois a literatura faz aparecer no já dito, no já ter sido dito o modo de se dizer, o acontecer do dizer. A literatura diz o dizer. Na literatura, torna-se aparente que o acontecimento exibe seu próprio acontecer sem metáforas. A literatura mostra o acontecer do dizer dizendo os acontecimentos, sendo assim radical ambigüidade. A literatura mostra o aparecer como a palavra da realidade. Por isso, é impossível para a literatura admitir que haja palavra de um lado e realidade de outro. O conto de Kafka "A Construção" revela a literatura em sua luta própria. Desejando controlar todo acontecimento, a construção mostra ambiguamente que essa tentativa de controlar é ela mesma um acontecimento. O desejo de controlar todo acontecer é tragicamente, perigosamente, ele mesmo, um acontecer. Nas descrições de Kafka, nas suas distopias, discronias, descentralizações, desterritorializações, todas essas experiências e elementos angustiantes descrevem não apenas as expressões kafkianas de nossa realidade política e burocrática, mas o acontecer nu e cru de um acontecer. Ler esse mostrar rude, nu, cru do acontecer do acontecer é muito difícil porque nenhuma metáfora, nenhuma analogia, nenhuma remissão a outro sentido pode nos ajudar a entrar no sentido. É que já sempre estamos "aí", na construção, no acontecer do sentido. Já sempre somos no ser. Ambigüidade é o elemento da literatura à medida que ambigüidade é o modo em que a tensão heraclítica dos contrários nos está sendo dada 
hoje: literatura é ambigüidade porque surge criadoramente na tensão trágica de sua própria morte - literalidade e erudição letrada. Nesse sentido, podemos entender quando Kafka diz em uma de suas cartas: "Sou outro do que aquilo que digo; falo outro do que eu penso, penso outro do que eu deveria pensar e isso até a obscuridade mais profunda". Na obra de Kafka, podemos descobrir outros modos de repensar a diferença para além da dialética das oposições, descobrindo a indistinção ambígua entre vida como processo e processo como Ge-stell (enquadramento, armação, burocracia), entre o acontecer-apropriador de ser e a construção incansável da Ge-stell, entre alienação e auto-esquecimento. Nesse habitar trágico, difícil, rude no âmbito da ambigüidade, a diferença entre filosofia e literatura pode descobrir um outro sentido de diferença - onde o outro não mais se chama "si mesmo" ou "outro", mas um "não-outro".

\section{* Marcia Cavalcante Schuback é professora da Södertörns University College/Suécia.}

${ }^{1}$ De acordo com Dora Diamant, esse conto foi escrito entre novembro e final de dezembro, no inverno de 1923/24. Cf. KAFKA, F. Kritische Ausgabe. Schriften, Tagebücher, Briefe, NIIA. Edição organizada por Jürgen Born e outros. Fischer: Frankfurt am Main, 1982 ff., p. 141. Para a versão de Kafka em língua portuguesa, cf. a primorosa traducão de Modesto Carone em KAFKA, F. Um artista da fome / A construcão. São Paulo: Companhia das Letras, 1998, p. 63-108.

2 Ibidem, p. 63.

${ }^{3}$ Cf. o comentário de Coetzee sobre o uso do tempo presente nesse conto de Kafka em Time, tempus and aspect in Kafka's Der Bau.

${ }^{4}$ Cf. a música de Chico Buarque chamada "Construção”.

${ }^{5}$ KAFKA, F. Op. cit., p. 63.

${ }^{6}$ Ibidem, pp. 64-65.

${ }^{7}$ Cf. as interpretacoes feitas por Walter Biemel desse conto de Kafka e de sua relacão com a questão da técnica em Heidegger. São três os textos de Biemel que tratam da relacão entre Heidegger e Kafka, sobretudo no tocante a esse conto tardio, "A Construção": um texto publicado já em 1968 no volume Philosophische Analysen zur Kunst der Gegenwart, Phaenomenologica, Bd 28; um de 1989, intitulado "Zur Deutung unserer Zeit bei Kafka und Heidegger" In: Kunst und Technik. Gedächtnisschrift zum 100 Geburtstag von M. Heidegger. Frankfurt:Vittorio Klostermann, 1989, pp. 425-439; e um outro com o título "Kafkas Dichten des Wohnens am Ende der Neuzeit". In: Kunst und Wahrheit. Studia Phaenomenologica, Bucharest: Humanitas, 2003.

${ }^{8}$ KAFKA, F. Über das Schreiben. Edição organizada por E. Heller e J. Beug. Framkfurt am Main: Fischer, 1969, p. 60. "Die Verwandschaft mit dem Tier ist leichter als die mit den Menschen [...]. Jeder lebt hinter einem Gitter, das er mit sich herumträgt. Darum schreibt man jetzt so viel von den Tieren. Es ist ein Ausdruck der Sehnsucht nach einem freien, natürlichen leben. Das natürliche leben für den Menschen ist aber das Menschenleben. Doch das sieht man nicht. Man will es nicht sehen. Das menschliche Dasein ist zu beschwerlich, darum will man es wenigstens in der Fantasie abschütteln".

${ }^{9}$ Cf. particularmente o texto de W. Biemel intitulado "Kafkas Dichten des Wohnens am Ende der Neuzeit”. In: Kunst und Wahrheit, Studia Phaenomenologica. Bucharest: Humanitas, 2003.

${ }^{10}$ Cf. minha traducão de "Construir, habitar, pensar". In: HEIDEGGER, M. Ensaios e conferências. Petrópolis: Vozes, 2002. 
${ }^{11}$ BIEMEL, W. Op.cit.

${ }^{12}$ AGAMBEN, G. Mezzi senza fine: note sulla politica. Torino: Bollati Boringhieri, 1996.

${ }^{13}$ Cf. HEIDEGGER, M; ARENDT, H. Briefe. Frankfurt am Main: Vittorio Klostermann, 1998.

${ }^{14}$ HEIDEGGER, M. Identität und Differenz. Stuttgart: Klett-Clotta, 2002, p. 26.

15 Ibidem.

${ }^{16}$ Cf. a discussão de W. Biemel sobre a relacão entre ficcão e abstração, no texto já citado, publicado em 2003 em Bucareste. 